\title{
Vertical sleeve gastrectomy improves liver and hypothalamic functions in obese mice
}

\author{
Peixin Li1,2,3, Zhijian Rao 2,3,4, Brenton Thomas Laing2,3,4, Wyatt Bunner2,3,4, Taylor Landry 2,3,4, Amber Prete2, \\ Yuan Yuan 2,3, Zhong-Tao Zhang 5 and Hu Huang2,3,4,6 \\ 'Department of Comprehensive Surgery, Medical and Health Center, Beijing Friendship Hospital, Capital Medical University, Beijing, People's Republic \\ of China \\ ${ }^{2}$ East Carolina Diabetes and Obesity Institute, East Carolina University, Greenville, North Carolina, USA \\ ${ }_{3}^{3}$ Human Performance Laboratory, College of Health and Human Performance, East Carolina University, Greenville, North Carolina, USA \\ ${ }^{4}$ Department of Kinesiology, East Carolina University, Greenville, North Carolina, USA \\ 5Department of General Surgery, Beijing Friendship Hospital, Capital Medical University, Beijing Key Laboratory of Cancer Invasion and Metastasis \\ Research \& National Clinical Research Center for Digestive Diseases, Beijing, People's Republic of China \\ ${ }^{6}$ Department of Physiology, East Carolina University, Greenville, North Carolina, USA
}

Correspondence should be addressed to Z-T Zhang or H Huang: zhangzht@ccmu.edu.cn or huangh@ecu.edu

\begin{abstract}
Vertical sleeve gastrectomy (VSG) is an effective surgery to treat obesity and diabetes. However, the direct effect of VSG on metabolic functions is not fully understood. We aimed to investigate if alterations in hypothalamic neurons were linked with perturbations in liver metabolism after VSG in an energy intake-controlled obese mouse model. C57BL/6 and hrNPY-GFP reporter mice received HFD for 12 weeks and were then divided into three groups: Sham (ad lib), Sham (pair-fed) with VSG and VSG. Food intake was measured daily, and blood glucose levels were measured before and after the study. Energy expenditure and body composition were determined. Serum parameters, liver lipid and glycogen contents were measured and gene/protein expression were analyzed. Hypothalamic POMC, AgRP/NPY and tyrosine hydroxylase-expressing neurons were counted. The following results were obtained. VSG reduced body weight gain and adiposity induced by HFD, increased energy expenditure independent of energy intake. Fed and fasted blood glucose levels were reduced in the VSG group. While serum active GLP-1 level was increased, the active ghrelin and triglycerides levels were decreased along with improved insulin resistance in VSG group. Liver lipid accumulation, glycogen content and gluconeogenic gene expression were reduced in the VSG group. In the hypothalamus, TH-expressing neuron population was decreased, and the POMCexpressing neuron population was increased in the VSG group. In conclusion, our data suggest that VSG improves metabolic symptoms by increasing energy expenditure and lowering lipid and glycogen contents in the liver. These physiological alterations are possibly related to changes in hypothalamic neuron populations.
\end{abstract}

Journal of Endocrinology (2019) 241, 135-147

\section{Introduction}

Obesity is a major risk factor for type 2 diabetes (T2D) (Kopelman 2000) and an important determinant of cardiovascular disease (Sharma 2003); thus, effective approaches for treating obesity and diabetes are needed. Vertical sleeve gastrectomy (VSG) is a surgical procedure that removes nearly $80 \%$ of the greater curvature of the 
stomach and is one of the most widely used bariatric procedures in the world due to its simplicity, low complication rates and consistent effect to induce a sustained, significant weight loss. As a result, it is a proven effective surgical operation to treat T2D (Henry et al. 2004, Sangeeta et al. 2013, Schauer et al. 2014).

Physiological alterations induced by VSG are significant, and investigation into these many changes is required to determine which are causally and functionally related to the observed bariatric surgery effects. For example, VSG reduces energy intake by restricting the capacity of stomach; therefore, many benefits are considered to be primarily from limited energy intake. Benefits include enhanced insulin action in skeletal muscle (Friedman et al. 1992), decreased fat content in adipose tissue (Dadson et al. 2016) and suppressed fat accumulation in the liver (Víctor et al. 2012). However, it is still unclear whether there are additive benefits from VSG when energy intake is controlled, such as during pair-feeding, in which mice from a 'pair-fed' group are given an amount of food that matches that eaten by the ad libitum VSG comparison group. This approach can elucidate a possible direct therapeutic mechanism of VSG, independent of food intake.

VSG has been shown to reverse T2D in more than $80 \%$ of patients undergoing the procedure (Vidal et al. 2008). Improved blood glucose levels have been observed as early as 3 days post operation before any significant weight loss (Rizzello et al. 2010), suggesting that skeletal muscle/adipose tissue glucose uptake and hepatic glucose production may play a direct role after VSG. Furthermore, recent clinical studies in humans have shown that improved glucose homeostasis and even diabetes remission may be related to increased nutrient-stimulated glucagon-like peptide (GLP)-1 and peptide YY (PYY) secretion after VSG, both of which have central effects (Peterli et al. 2009).

Areas in the central nervous system involved in control of energy balance include hindbrain with the area postrema (AP), the nucleus of the solitary tract (NTS), the lateral parabrachial nucleus (PBN) and the hypothalamus (Schwartz et al. 2000). Within the hypothalamus, AgRP/NPY and POMC-expressing neurons are critical for the maintenance of body weight and glucose homeostasis (Schwartz et al. 2000, Ruud et al. 2017). Peripheral signals that induce changes in eating behavior and energy expenditure after VSG need to be transmitted to the brain. This may occur either via vagal or non-vagal afferent nerve signaling or directly via blood circulation (Berthoud 2008).
However, it remains largely unclear precisely whether gut-generated signals are responsible for the hypothalamus structure/function after VSG.

Unlike the obvious improved metabolic phenotypes, the physiological mechanisms underlying the effects of VSG surgery, independent of food intake, are currently not fully understood. In this present study, we aim to investigate the physiological adaptations in skeletal muscle, and liver in conjunction with hypothalamic neurons in response to VSG utilizing a pair-fed HFD-induced obesity mouse model.

\section{Methods and materials}

\section{Experimental animals}

Six-week-old C57BL6 male mice (JAX Stock No: 00664: $n=24$ ) and B6.FVB-Tg (NPY-hrGP)1Lowl/J mice (JAX Stock No: 006417: $\mathrm{n}=18$ ) from Jackson lab (The Jackson Laboratory) were housed under controlled temperature and lighting conditions of $20-22^{\circ}$ and 12-h lightdarkness cycle. Once the experimental protocol was initiated, all mice were divided into three groups: Sham (ad lib), Sham (pair-fed) with VSG group and VSG groups, all under HFD conditions (17\% protein, 58\% fat and 25\% carbohydrate, energy density $5.56 \mathrm{kcal} / \mathrm{g}$, Research Diets D12331; Research Diets, Inc.) for 12 weeks. Each cage accommodated one mouse. All aspects of animal care and experimentation were conducted in accordance with the National Institutes of Health Guide for the Care and Use of Laboratory Animals (National Institutes of Health Publication No. 85-23, revised 1996) and approved by the Institutional Animal Care and Use Committees of East Carolina University.

\section{VSG Surgery}

VSG surgery was initiated using isoflurane anesthesia. The lateral $80 \%$ of stomach was resected by using a $12.26 \mathrm{~mm}$-long sterile titanium clip (LT400, Ethicon US LLC, Johnson \& Johnson, Santa Ana, CA, USA) to identify and mark the incision path, followed by closing the stomach incision with a sterile clip applier (LC407, Ethicon US LLC, Johnson \& Johnson), thus, leave a tubular gastric remnant in continuity between the esophageal sphincter and the pylorus. The Sham surgery involved opening the peritoneal cavity and applying manual pressure with blunt forceps between the esophageal sphincter and the pylorus. Mice were fully fasted (no food or water) for the first $24 \mathrm{~h}$ post surgery, 
and $0.9 \%$ sodium chloride $(20 \mathrm{~mL} / \mathrm{kg}$; Hospira, San Clemente, CA, USA) was injected subcutaneously every $8 \mathrm{~h}$. 20\% glucose and electrolyte solution were provided to mice on the second day post surgery, while gel (DietGel Recovery; ClearH2O, Portland, ME, USA) and liquid diet (Ensure Original Nutrition Powder, Vanilla; Abbott) were provided to mice ad libitum for the following 5 days. HFD was provided to mice from the eighth day post surgery until the end of the experiment.

\section{Energy intake, energy expenditure and body composition}

Food intake was measured 2 weeks after surgery over a 5-7-day period, the data was combined, averaged and analyzed. Fresh pellets of food were provided every day to avoid temperature-dependent spoiling of the HFD, and cages were changed every time food weight was measured. Any residual food in the bedding was included in measurements. Cumulative food intake data were obtained by adding all intake measurements during the study.

Fat and lean body mass were assessed using Echo MRI (Echo Medical Systems Houston, TX, USA). Energy expenditure was measured by indirect calorimetry using CLAMS (TSE PhenoMaster, Germany) 1 week before killing. Mice were acclimated in the CLAMS chambers for $72 \mathrm{~h}$ before data collection and had access to food and water for the duration of the studies.

\section{Glucose level measurement}

A glucose meter was used to measure blood glucose levels (Relion prime Blood Glucose Monitoring System; ARKRAY INC., Kyoto, Japan). Fed glucose levels were collected at 8:00h on the day of operation and 3 days before the end of the experiment, respectively. Fasted glucose levels were collected at 8:00 h, after a 12-h fast, 3 days before operation, and on the day when mice were killed.

\section{Measurement of insulin, ghrelin, GLP-1 and} triglyceride levels in serum

Blood was collected from the neck vein plexus by the end of experiment. Blood samples were centrifuged at $1504 \mathrm{~g}$ at $4^{\circ} \mathrm{C}$ for $5 \mathrm{~min}$. Serum insulin, active ghrelin and active GLP-1 levels were measured with MILLIPLEX MAP Mouse Metabolic Hormone Magnetic Bead Panel Metabolism Multiplex Assay (MMHMAG-44K, Millipore).
Serum triglycerides level was measured with Triglyceride Assay Kit (ab65336, Abcam).

\section{Determination of insulin resistance by homeostasis model assessment of insulin resistance (HOMA-IR) analysis}

HOMA-IR analysis was used to assess insulin resistance in mice. After overnight fasting at the end of study, values for HOMA-IR were calculated from the values of fasting serum glucose $(\mathrm{mg} / \mathrm{dL})$ and fasting serum insulin $(\mu \mathrm{U} / \mathrm{mL})$ by using the following formula: fasting glucose value $(\mathrm{mg} / \mathrm{dL}) \times$ fasting insulin value $(\mu \mathrm{U} / \mathrm{mL}) / 405$.

\section{Tissue collection}

Mice from each group were euthanized by isoflurane, and gastrocnemius muscle and liver were removed. Samples were immediately flash-frozen in liquid nitrogen temporarily. After all tissues are collected, tissues were stored at $-80^{\circ} \mathrm{C}$ freezer until further analysis. For brain samples, the mice were perfused intracardially with phosphate-buffered saline, followed by $10 \%$ formalin at the end of experiments. The brains were then collected and fixed in $10 \%$ formalin overnight, and finally transferred to $30 \%$ sucrose solution as previously described (Huang et al. 2012, 2013).

\section{Morphological analysis of the liver}

Livers were frozen in liquid hydrogen and then cryostatsectioned at a thickness of $5 \mu \mathrm{M}$ onto poly-L-lysine slides for lipid deposition analysis by Oil Red O staining. The red areas and adipocyte size were quantified by ImageJ.

\section{Immunohistochemistry}

For fluorescence detection of POMC and AgRP/NPYexpressing neurons, brains were coronally sectioned and immunohistochemistry was performed as previously described (Huang et al. 2012, 2013). Briefly, 20 $\mu \mathrm{M}$ brain sections were incubated with antibody to POMC (Phoenix Pharmaceuticals) and tyrosine hydroxylase (Millipore Sigma), followed by incubation with fluorescent-labeled secondary antibodies. AgRP/NPY neurons were identified in sections by native fluorescence (green) of the green fluorescent protein (GFP) transgene. POMC, NPY and TH-positive neurons throughout the medio-basal hypothalamus were counted using ImageJ software. Three serial sections were analyzed in each mouse $(n=3-5)$. 


\section{Quantitative real-time PCR}

Total RNA from liver was extracted using TRIzol reagent (Invitrogen) and subjected to quantitative real-time PCR as described (Do et al. 2018). Gene-specific primer sequences are listed in Supplementary Table 1 (see section on supplementary data given at the end of this article). Relative gene expressions were calculated with the deltadelta CT method with glyceraldehyde 3-phosphate dehydrogenase (GAPDH) RNA normalization, using ViiA 7 system (Applied Biosystems).

\section{Western blot analysis}

Western blot analysis was performed as described previously (Laing et al. 2016). Briefly, liver lysis (60 $\mu \mathrm{g}$ protein) were separated by SDS-PAGE and transferred to nitrocellulose membranes. Membranes were incubated with antibodies against phosphorylated serine 473 of AKT (\#9271) and threonine 705 STAT3 (\#9131), as well as total AKT (\#9272) and total STAT3 (\#9139) (Cell signaling). The bands were visualized with enhanced chemiluminescence and quantified by densitometry. The levels of phosphorylated proteins were normalized to the total protein levels.

\section{Statistical analysis}

Data are presented as the mean \pm standard error of the mean (s.E.M.). Within-group comparisons between preoperation and post-operation were analyzed by paired $T$ test. Comparisons among groups were analyzed by using one-way ANOVA followed by Dunnett's correction for multiple comparisons to determine pair-wise differences between groups. Data were analyzed by using IBM SPSS Statistics 20 (IBM Analytics) and GraphPad Prism, version 8.0 (GraphPad Software). $P<0.05$ denoted significance.

\section{Results}

\section{VSG mitigates HFD-induced body weight gain and adiposity partially independent of food intake}

As shown in Fig. 1A, 80\% of the stomach was removed in the VSG group. To avoid any effects from reductions in food intake after VSG operation, we used another control group Sham (pair-fed) with the VSG group. As shown in Fig. 1C, both Sham (pair-fed) group and VSG groups had similar energy intake (pair-fed: $12.5 \pm 0.1$; VSG: $12.5 \pm 0.2 \mathrm{kcal}$ ), which was significantly less than the Sham (ad lib) group $(13.5 \pm 0.2 \mathrm{kcal})$.
A Vertical Sleeve Gastrectomy

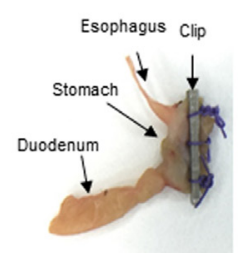

\section{B} Body weight (Pre/Post \%)

\section{C}

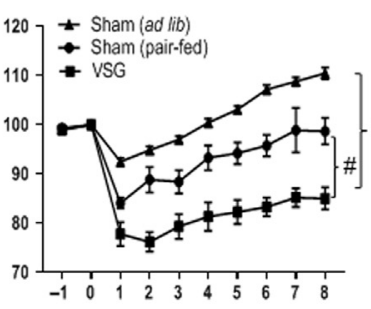

Weeks after surgery

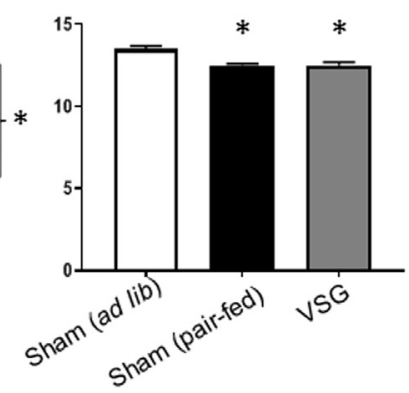

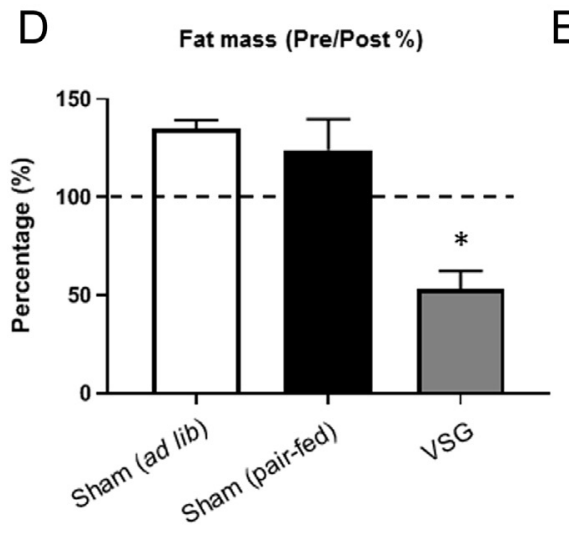

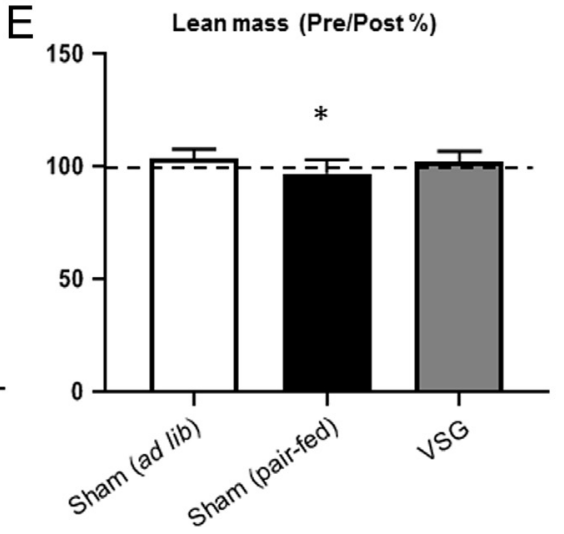

Figure 1

Vertical sleeve gastrectomy mitigates HFD-induced body weight gain and adiposity independent of food intake. (A) Representative image of VSG by titanium clip. (B) Percentage changes in body weight, (C) food intake, (D) percentage change in fat mass, (E) percentage change in lean mass in Sham (ad lib), Sham (pair-fed) and VSG groups under HFD condition $(n=8), * P<0.05$ vs Sham (ad lib), $\# P<0.05$ vs Sham (pair-fed). 
As shown in Fig. 1B, there were no differences in body weight among the three groups at the beginning of the study. However, the VSG group had significantly decreased body weight compared to the Sham (pair-fed) group after only a week after operation, while the Sham (pair-fed) group also experienced significantly decreased body weight compared with Sham (ad lib) (Fig. 1B).

Echo MRI data revealed that there were increases in percent change of fat mass post-operation compared with pre-operation in the Sham (ad lib) group (135.2 $\pm 10.8 \%)$ and Sham (pair-fed) group $(124 \pm 38.3 \%)$, respectively. However, 8 weeks after VSG surgery, the VSG group showed significant decreased in percent change of fat mass postoperation compared to pre-operation $(53.2 \pm 22.4 \%)$, and this percent change in fat mass was also significantly lower than Sham groups (Fig. 1D). Data also indicated that there was a significant reduction in percent change of lean mass in the Sham group (pair-fed) $(96.6 \pm 3.0 \%)$ post operation compared with pre operation. In contrast, the Sham (ad lib) group (103.9 $\pm 4.1 \%)$ had increased lean mass post operation compared to pre operation, while the VSG group (101.8 $\pm 3.0 \%)$ had maintained their lean mass (Fig. 1E).

\section{VSG reduces body weight via increased energy expenditure}

Energy expenditure measured by oxygen consumption over $24 \mathrm{~h}$ was significantly increased in the VSG group both during the night and day $\left(3067 \pm 255 \mathrm{ml} \mathrm{h}^{-1} \mathrm{~g}^{-1}\right)$
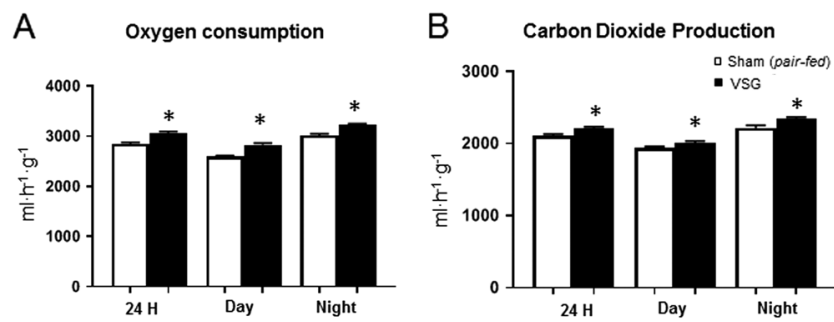

C
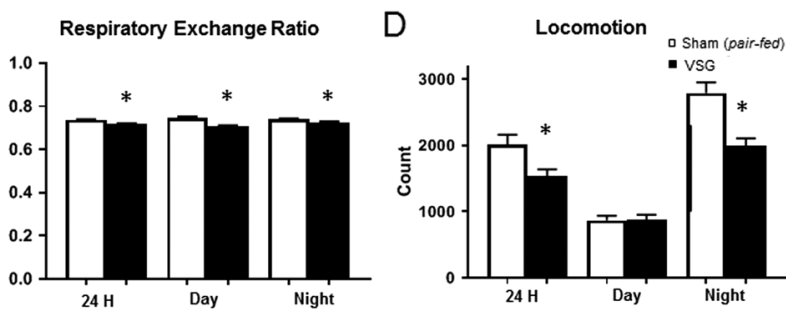

Figure 2

VSG reduces body weight via increased energy expenditure. (A) Corresponding 12-h average during day, night phases and $24 \mathrm{~h}$ of oxygen consumption, (B) carbon dioxide production, (C) respiratory exchange ratio, (D) locomotion activity at the age of 25 weeks in Sham (pair-fed), and VSG groups under HFD condition $(n=8)$, $p<0.05$ vs Sham (pair-fed). compared to the Sham (pair-fed) group $\left(2847 \pm 243 \mathrm{ml} \mathrm{h}^{-1} \mathrm{~g}^{-1}\right)$ (Fig. 2A). Similarly, $\mathrm{CO}_{2}$ production over $24 \mathrm{~h}$ was also significantly increased in the VSG group $\left(2205 \pm 98 \mathrm{ml} \mathrm{h}^{-1} \mathrm{~g}^{-1}\right)$ compared with the Sham (pair-fed) group $\left(2103 \pm 219 \mathrm{ml} \mathrm{h}^{-1} \mathrm{~g}^{-1}\right)$ (Fig. 2B). As shown in Fig. 2C, the Sham (pair-fed) group had elevated RER $(0.74 \pm 0.03)$, but this was reduced by VSG in both night and day time (0.72 \pm 0.04$)$ indicating increased fat utilization. (Fig. 2C). Locomotor activity was significantly lower in the VSG group (1543 \pm 526 count) during the night phase compared with Sham (pair-fed) (2013 \pm 477 count).

\section{VSG improves hyperglycemia and insulin resistance in HFD-induced obese mouse model}

To determine whether VSG improves the glucose profile induced by high-fat diet, we measured fed status glucose levels before and after this experiment. As shown in Fig. 3A, although there were no significant differences in fed status glucose levels pre- and post-surgery in the
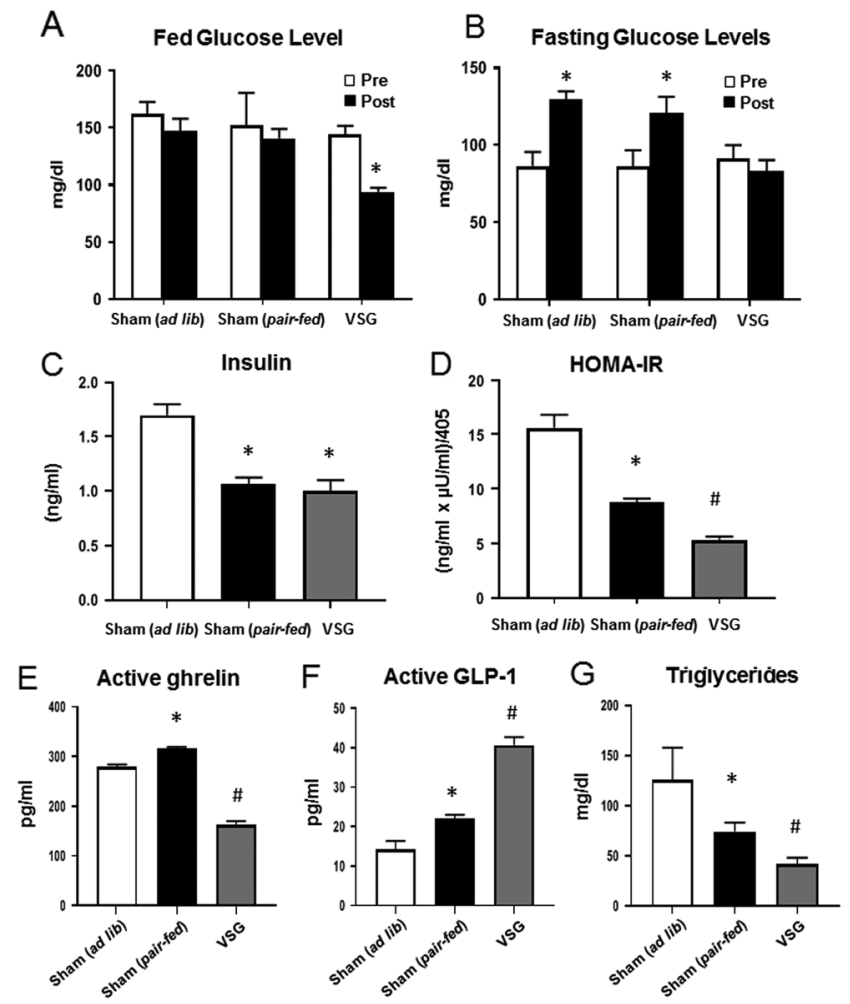

\section{Figure 3}

VSG improves hyperglycemia and insulin resistance in HFD-induced obese mouse model. (A) Fed glucose levels, (B) fasted glucose, (C) insulin, (D) HOMA-IR, (E) ghrelin, (F) GLP-1 and (G) triglyceride levels at the age of 26 weeks of Sham (ad lib), Sham (pair-fed) and VSG groups under HFD condition $(n=3-8) .{ }^{*} p<0.05$ vs pre-operation. ${ }^{*} P<0.05$ vs Sham (ad lib), $\# P<0.05$ vs Sham (pair-fed). 
Sham (ad lib) group (Pre: $162 \pm 11$; Post: $147 \pm 11 \mathrm{mg} / \mathrm{dL}$ ) and the Sham (pair-fed) group (Pre: 153 \pm 28 ; Post: $141 \pm 8 \mathrm{mg} / \mathrm{dL}$ ), fed plasma glucose levels in the VSG group were significantly reduced Post-VSG compared with Pre-VSG (Pre: $145 \pm 7$; Post: $94 \pm 4 \mathrm{mg} / \mathrm{dL}$ ) (Fig. 3A). Fasted glucose levels were significantly higher at the end of the experiment in both Sham (ad lib) group (Pre: $87 \pm 9$; Post: $130 \pm 5 \mathrm{mg} / \mathrm{dL}$ ) and the Sham (pair-fed) group (Pre: $86 \pm 11$; Post: $121 \pm 11 \mathrm{mg} / \mathrm{dL})$. In the VSG group, these elevations in glucose over time were abolished (Pre: 92 \pm ; Post: $83 \pm 7 \mathrm{mg} / \mathrm{dL}$ ) (Fig. 3B). HOMA-IR was calculated by fasting glucose and insulin levels as an indication of insulin resistance. Figure 3D shows that the VSG group has improved HOMA-IR by nearly three-fold $(5.3 \pm 0.2)$ compared with Sham (ad lib) (15.6 \pm 0.7$)$, while the Sham (pair-fed) group also improved significantly $(8.7 \pm 0.2)$. In addition, serum triglycerides levels were significantly decreased in the Sham (pair-fed) group $(74 \pm 5 \mathrm{mg} / \mathrm{dL}$ ) compared with Sham (ad lib) $(126 \pm 18 \mathrm{mg} / \mathrm{dL})$ and was further reduced in the VSG group ( $42 \pm 4 \mathrm{mg} / \mathrm{dL}$ ) (Fig. 3G).

Serum active ghrelin levels were elevated in the Sham (pair-fed) group $(316 \pm 4 \mathrm{pg} / \mathrm{mL})$ compared with Sham (ad lib) $(279 \pm 5 \mathrm{pg} / \mathrm{mL})$ and were significantly reduced in the VSG group $(163 \pm 7 \mathrm{pg} / \mathrm{mL})$ (Fig. 3E). In contrast, serum levels of active GLP-1 were higher in the Sham (pair-fed) group $(22 \pm 1 \mathrm{pg} / \mathrm{mL})$ compared with Sham (ad lib) $(14 \pm 2 \mathrm{pg} / \mathrm{mL})$ and were further increased in VSG group $(41 \pm 2 \mathrm{pg} / \mathrm{mL})$ (Fig. $3 F)$.

\section{VSG enhances key signaling pathways in the liver}

In support of the notion that VSG attenuates hyperglycemia induced by HFD, key signaling in gastrocnemius muscle and liver was examined by immunoblotting for phosphorylation of AKT (Protein kinase B) and STAT3. While there was no detectable phosphorylation signaling among groups in gastrocnemius muscle (data not shown), both phosphorylation of AKT and STAT3 to be elevated in the VSG group (pAKT:1750 $\pm 1035 \%$; pSTAT3: $3270 \pm 1649 \%$ ), while the other two groups revealed minimal detectable signals (Fig. $4 \mathrm{~A}$ and $\mathrm{B}$ ).

\section{VSG reduces HFD-induced lipid accumulation in liver}

Histological analysis using Oil Red O staining showed that lipid accumulation occurred in the liver of Sham (ad lib) group, while the Sham (pair-fed) group (18.5 $\pm 1.5 \%)$ showed significantly reduced lipid accumulation compared with Sham (ad lib) group (30.3 $\pm 3.2 \%)$. The VSG group $(6.8 \pm 3.5 \%)$ experienced even further reductions in

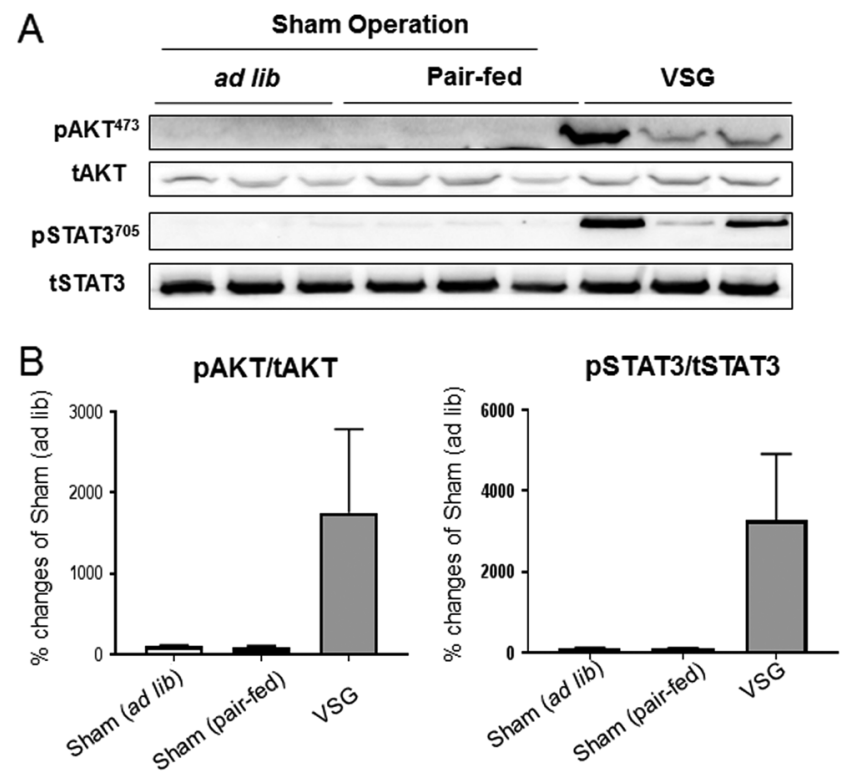

Figure 4

VSG enhances key signaling pathways in the liver. (A) Representative images of western blot, and (B) normalized graphs show AKT and STAT3 signaling in liver by the end of the study from the Sham (ad lib), Sham (pair-fed) and VSG groups $(n=3)$.

liver lipid accumulation compared with Sham (pair-fed) group (Fig. 5).

\section{VSG alters key gene expression related to glycogen synthesis and glycogen content in liver}

At the end of experiment, gene expressions of key enzymes were examined. Liver-expressed antimicrobial peptide 2 (LEAP2) is produced in the liver and small intestine, and its secretion is suppressed by fasting and caloric restriction (Ge et al. 2018). Consistent with previous findings, in both VSG $(0.57 \pm 0.25)$ and Sham (pairfed) groups $(0.54 \pm 0.05)$, liver LEAP2 mRNA levels were significantly decreased compared with the Sham (ad lib) group (1.00 \pm 0.06$)$. Liver-type pyruvate kinase (L-PK) level was only decreased in the VSG group $(0.53 \pm 0.10$ versus Sham pair-fed: $1.36 \pm 0.09$; and Sham (ad lib): $1.00 \pm 0.07$ ). Glucokinase (GK) mRNA level was increased in the Sham (pair-fed) group $(2.13 \pm 0.28)$ compared with Sham (ad lib) group (1.00 \pm 0.17$)$, but significantly reduced in VSG group $(0.76 \pm 0.22)$ compared with Sham (pair-fed) group (2.13 \pm 0.28$)$. Glucose-6-phosphatase (G6Pase) gene expression was significantly decreased in the VSG group $(0.34 \pm 0.04)$ compared with two Sham groups (Sham

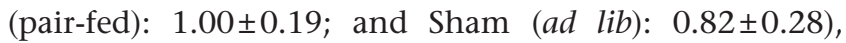
while there was no difference in the mRNA expression of G6Pase between Sham (ad lib) and Sham (pair-fed) group. 


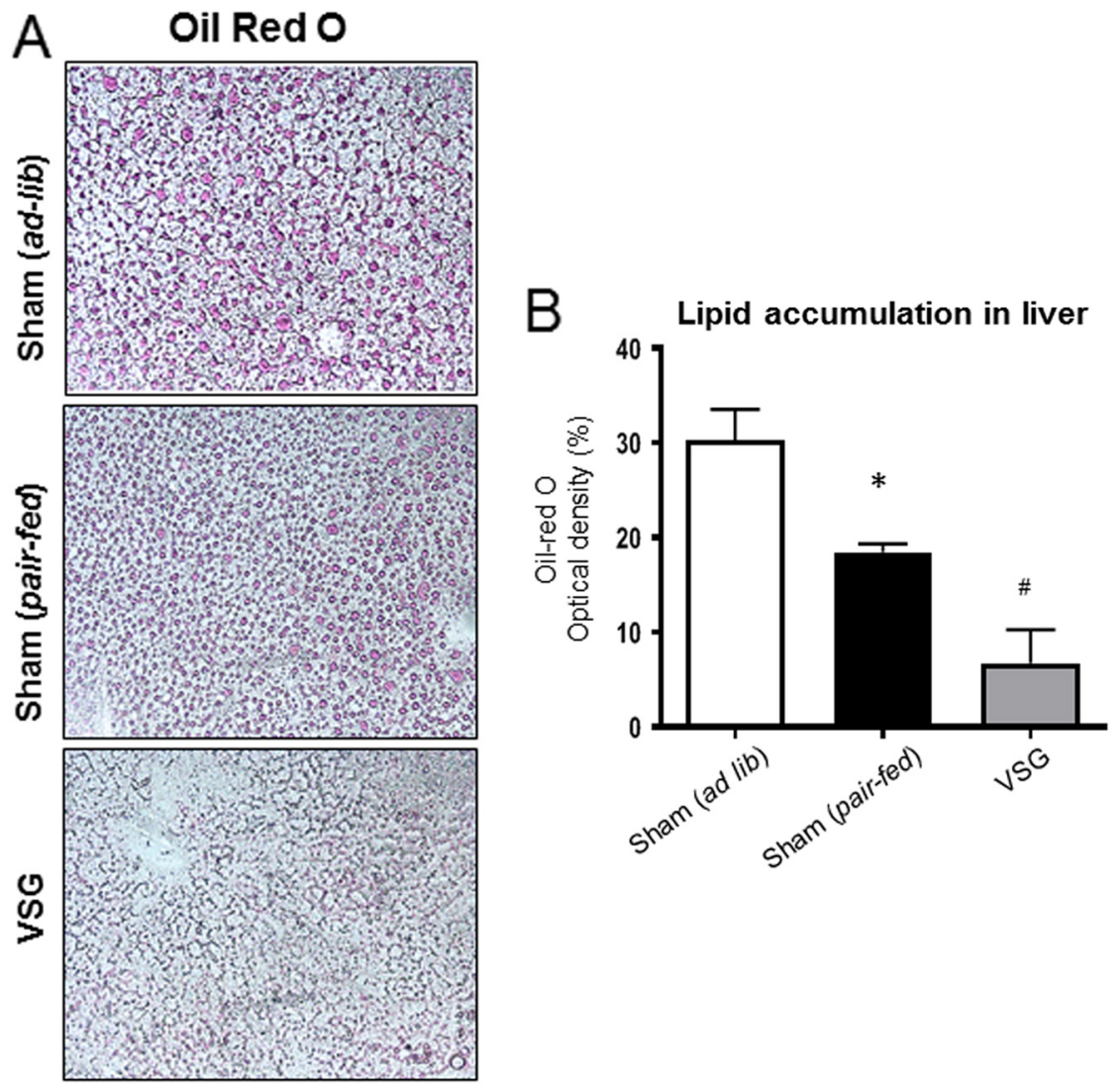

\section{Figure 5}

VSG reduces HFD-induced lipid accumulation in liver. (A) Representative images of Oil Red O staining, and (B) quantification graph by the end of the study in the Sham (ad lib), Sham (pair-fed) and VSG groups $(n=3)$. * $P<0.05$ vs Sham (ad lib), $\# P<0.05$ vs Sham (pair-fed).
(Fig. 6A). Furthermore, glycogen was extracted and measured from liver samples of all three groups (Fig. 6B), and there was significantly decreased glycogen content only in VSG group $(6.3 \pm 2.3 \mu \mathrm{g} / \mathrm{mg})$ versus other two controls (Sham (ad lib): 15.1 \pm 2.6 ; Sham (pair-fed): $14.5 \pm 1.8 \mu \mathrm{g} / \mathrm{mg})$.

\section{Effects of VSG on hypothalamic neurons}

To determine the effect of VSG on hypothalamic neurons, hrNPY-GFP Reporter mice were utilized to investigate NPY/AgRP-expressing neurons, and immuno-labeling with an anti-POMC antibody was performed to stain POMC-expressing neurons. There were no differences in amount of NPY/AgRP expressing neurons among the three groups (Sham (ad lib) : 99 \pm 5 ; Sham (pair-fed): 97 \pm 7 ; VSG: $89 \pm 11$ Count); however, VSG significantly increased the number of POMC-expressing neurons compared with

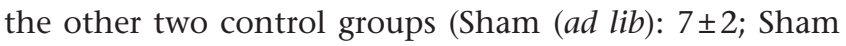
(pair-fed): $9 \pm 2$; VSG: $13 \pm 5$ Count) (Fig. 7A and B). In addition, tyrosine hydroxylase (TH)-expressing neurons were decreased in Sham (pair-fed) group (16 \pm 2 count)

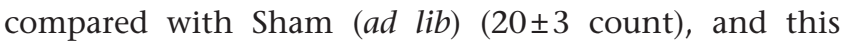
neuron population was further decreased in VSG group (12 \pm 2 count) (Fig. 8). Printed in Great Britain

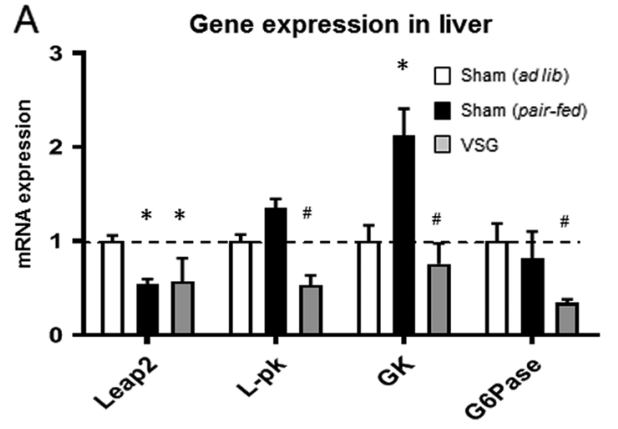

B Glycogen content in liver

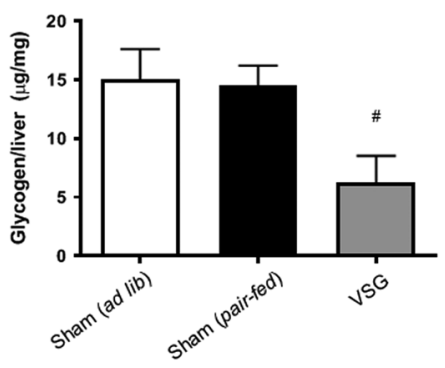

Figure 6

VSG alters key gene expression related to glycogen synthesis and glycogen content in liver. (A) Gene expression of Leap2, L-PK, GK and G6pase in the liver. (B) Liver contents from the Sham (ad lib), Sham (pair-fed) and VSG groups $(n=6) . * P<0.05$ vs Sham (ad lib), $\# P<0.05$ vs Sham (pair-fed). 
A
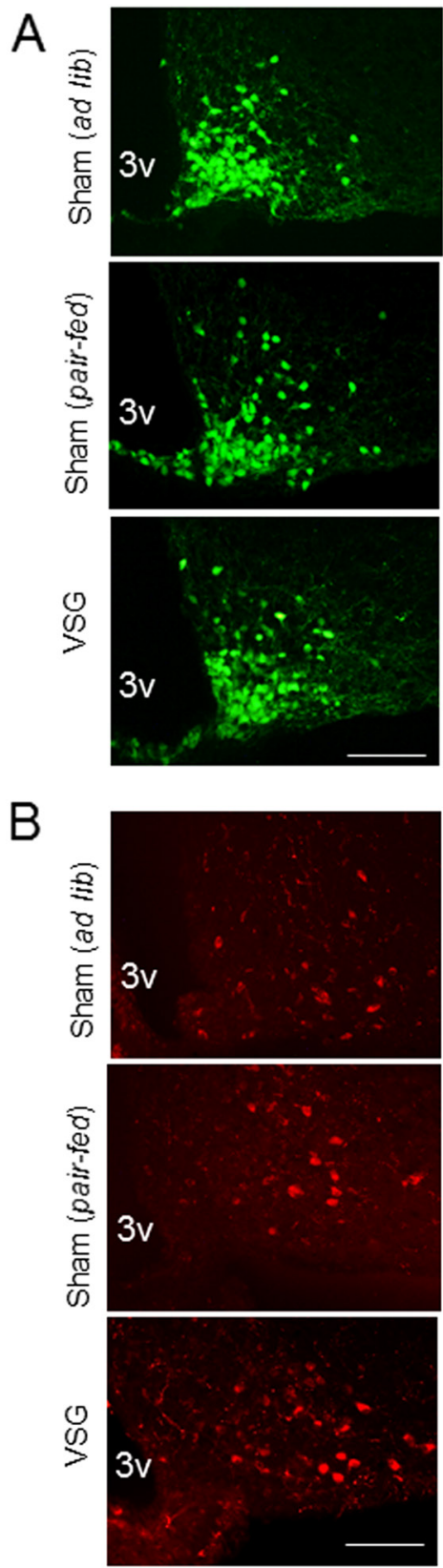

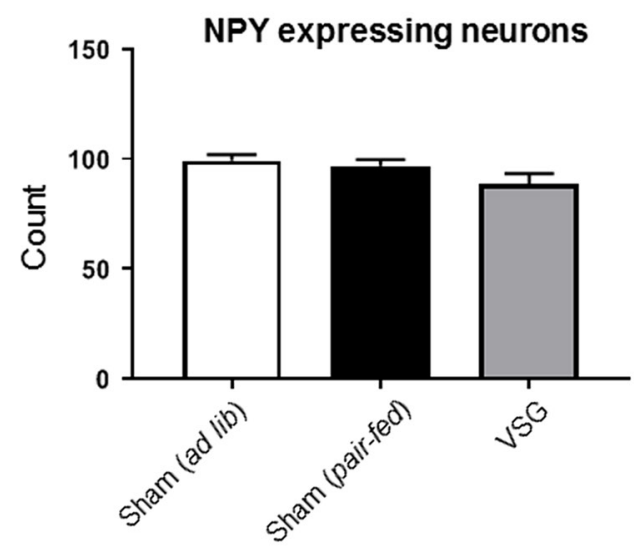

POMC expressingneurons

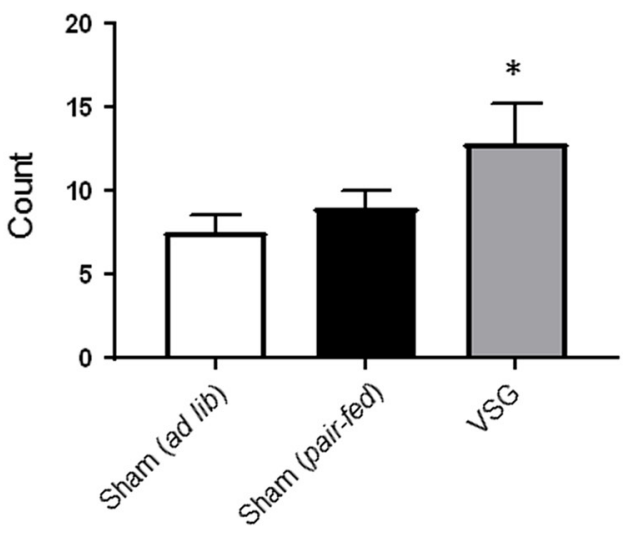

\section{Figure 7}

VSG increases POMC-expressing neurons in arcuate of hypothalamus. (A) Representative images of immunofluorescence and qualification of AgRP/NPY-expressing neurons of

hypothalamic sections from the Sham (ad lib),

Sham (pair-fed) and VSG groups $(n=3-5)$. (B) Representative images of immunofluorescence of POMC-expressing neurons and qualification of POMC-expressing neurons of hypothalamic sections from the Sham (ad lib), Sham (pair-fed) and VSG groups $(n=3-5)$. $* P<0.05$ vs Sham (pair-fed). $3 \mathrm{~V}$ : third ventricle, scale bars represent $50 \mu \mathrm{M}$.

\section{Discussion}

VSG is a worldwide recognized weight loss treatment. To date, studies have debated whether restriction of stomach capacity is the only reason for weight loss and enhanced metabolic function. Indeed, one of the original aims of VSG surgery was to induce mechanical restriction to elicit reduced food intake, and while this approach is effective, it ignored other direct effects of VSG independent from suppressed energy intake. This includes changes in glucose homeostasis and even diabetes remission before changes in body weight. The pair-feeding approach performed in this study isolates potential causal factors independent from altered food intake by VSG operation. In this study, we observed that despite the equal energy intake in VSG and Sham (pair-fed) group, the VSG group displayed reduced body weight and adiposity, primarily associated with increased energy expenditure. Of note, the energy expenditure data presented in this study were normalized by total body weight instead of lean mass. While it is true that adipose tissue is metabolically less active than the skeletal muscle or liver, adipose tissue comprises a large proportion of body mass, especially in high-fat dietinduced obese individuals. Also, some of the fat mass 


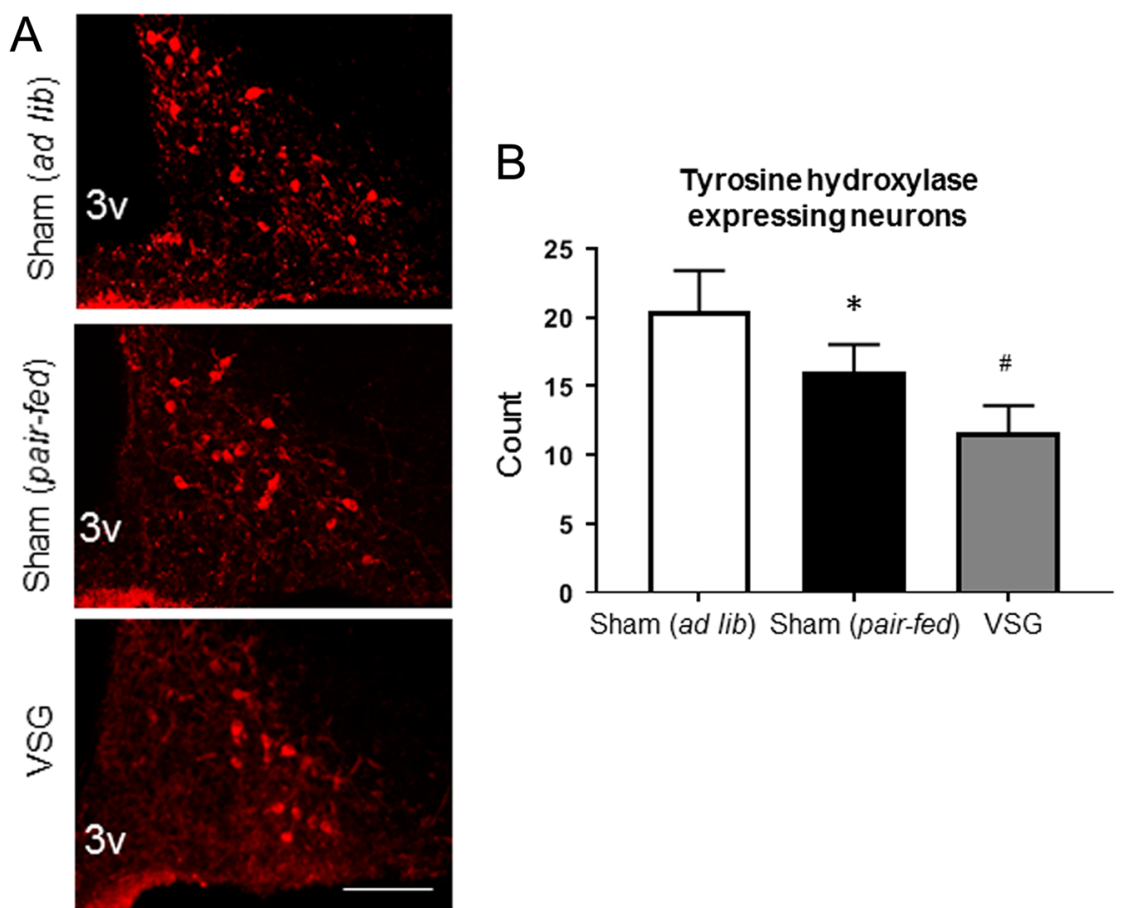

\section{Figure 8}

VSG decreases tyrosine hydroxylase (TH)expressing neurons in arcuate of hypothalamus. (A) Representative images of immunofluorescence and (B) qualification of tyrosine hydroxylaseexpressing neurons of hypothalamic sections from the Sham (ad lib), Sham (pair-fed) and VSG groups $(\mathrm{n}=3-5) .{ }^{*} P<0.05$ vs Sham (ad lib), $\# P<0.05$ vs Sham (pair-fed). 3V, third ventricle, scale bars represent $50 \mu \mathrm{M}$. includes brown/beige fat (Florian et al. 2017), which is metabolically active, especially during thermoregulation (Wu et al. 2012). Moreover, white adipose tissue is an endocrine tissue, and secreted adipokines, such as leptin and adiponectin, may drive metabolism in lean tissues (Kershaw \& Flier 2004). Interestingly, locomotion activity often contributes to total energy expenditure; however, in this study, we observed a significant reduction of locomotion activity in VSG group, primarily during the night time. This reduced locomotor activity may due to decreased food seeking behavior possibly due to hypothalamic signaling alterations.

Our findings agree with previous studies demonstrating that the fed glucose levels are significantly decreased only in the VSG group compared with the pair-fed VSG Sham group (Cummings et al. 2012). Furthermore, in the fasting state while hyperglycemia progressed with age in both Sham ad lib and Sham pair-fed groups, the VSG group maintained the same glucose levels as before the VSG operation. Notably, this improvement in glucose profile is independent from food intake and was also observed on day 1 after the VSG operation (data not shown). Moreover, fasting insulin levels were also lower in the VSG group, accompanied by improved insulin resistance illustrated by HOMA-IR. These data clearly demonstrate that VSG improves hyperglycemia and insulin resistance induced by HFD. Recently, it has been reported that glucagon-like peptide-1(7-36) amide (GLP-1) acts as a secreted peptide that enhances pancreatic insulin secretion and suppresses pancreatic glucagon secretion to regulate blood glucose homeostasis (Prashant et al. 2014). Consistent with previous findings, serum GLP-1 levels were significantly higher in the VSG group compared with the two Sham groups, suggesting a potential mechanism for VSGmediated reduced glucose levels. Interestingly, a recent publication suggested that GLP-1 action in $\beta$-cells does not contribute to VSG-improved glucose profiles (Douros et al. 2018), indicating other metabolic organs might be involved in the event. Metabolic organs such as skeletal muscle via glucose uptake (Holman \& Cushman 1994) and liver via gluconeogenesis (Petersen et al. 2017) contribute to reduced blood glucose levels. Considering this, we investigated the key signaling pathways involved in skeletal muscle glucose uptake and liver glucose output. Surprisingly, there was no detectable signaling in basal phosphorylation of AKT and STAT3 in skeletal muscle (data not shown); however, we observed a possible enhanced signaling in phosphorylation of both AKT and STAT3 in liver samples of the VSG group compared with the other two control groups. Analysis of AKT and STAT3 signaling was limited by small sample size; however, these strong trends despite low statistical power are encouraging and justify future investigation. Corresponding to the altered hepatic signaling, liver glycogen content was significantly decreased in VSG group. Consistently, the gene expression related to hepatic glucose production was also reduced in the VSG group but not in the control groups. Histological analysis further revealed that lipid accumulation was 
significantly reduced in the VSG group compared with control groups. These data indicate that HFD-induced glucose and lipid profiles can be ameliorated by VSG surgery by, at least in part, improving hepatic function independent of energy intake.

One possible mechanism to explain the energy intake-independent glucose lowing effect of VSG is modulation of vagus nerve activity. The vagus nerve is a key signaling relay system between the gastrointestinal tract and the brain, playing a prominent role in energy and glucose homeostasis (Berthoud 2008). Vagal afferent fibers in the foregut include mucosal mechanoreceptors, chemoreceptors and tension receptors, which take sensory information from the gut to the brainstem (Iggo 1957). Physical restructure of the stomach may result in the impairment of this signaling. Although it has been reported that the density of vagal afferents in the NTS and DMV is significantly elevated after VSG compared to Sham-operated rats (Ballsmider et al. 2015), the precise role of the vagus nerve in satiation and its interactions with the CNS is still unclear. On the other hand, vagal nerve damage might result in long-term reorganization of feeding centers with reduced vagal input and glutamate release in the hypothalamus. Notably, the anorexigenic hormone PYY is released from the distal intestine after a meal, suggesting reflex paracrine signaling via the vagus nerve (Murphy \& Bloom 2006). Interestingly, PYY also influences energy homeostasis through hypothalamic POMC and NPY neurons to suppress food intake (De Silva \& Bloom 2012). Thus, investigation into the effects of VSG on hypothalamic neurons is needed, since it has been reported that there are dual connections between hypothalamic neurons and liver which are highly involved in energy and glucose homeostasis (Uyama et al. 2004).

The orexigenic Agouti-related peptide (AgRP)expressing neuron within the ARC controls food intake and energy expenditure (Luquet et al. 2005). Due to lack of reliable antibody agonists of AgRP or NPY, we utilized hrNPY-GFP-Reporter mice to investigate the effects of VSG on NPY/AgRP expressing neurons. Interestingly, the number of NPY-expressing neurons was not different in all three groups. Recent studies have reported that AgRP/NPY neurons are not required for the regulation of energy homeostasis in mice when AgRP/NPY was deleted from neonates, suggesting that other pathways capable of regulating energy homeostasis can compensate for the loss of both AgRP and NPY (Qian et al. 2002). Indeed, dopaminergic neuron activity is an important contributor to energy intake when AgRP neuron activity is chronically compromised under a high-fat diet (Denis et al. 2015), therefore, we investigated the effects of VSG on the hypothalamic dopaminergic neuron population in HFD-induced obese mice. We found that arcuate dopaminergic neuron number was decreased in the Sham (pair-fed) group compared with Sham (ad lib) and were further decreased in VSG group. This result is reminiscent of a recent study showing that ghrelin action on arcuate dopaminergic neurons is sufficient to monitor metabolic status (Zhang \& van den Pol 2016). In contrast, the number of POMC-expressing neurons was significantly elevated in the VSG group versus the other two control groups. To our knowledge, this is the first study showing that VSG has a contradictory effect on arcuate dopaminergic and POMC-expressing neuron number.

POMC-expressing neurons are mainly located in the ARC of the hypothalamus and in the nucleus of solitary tract (NTS) in the brain stem. Activation of POMCexpressing neurons has been shown to trigger alphamelanocyte stimulating hormone $(\alpha-\mathrm{MSH})$ production and release from POMC-expressing neurons, which in turn activates melanocortin receptor 4 (MC4R) leading to suppressed food intake and increased energy expenditure (Dietrich \& Horvath 2013). A recent study found that postnatal inhibition of POMC neurons in the ARC nucleus (but not in the NTS) increased food intake, reduced energy expenditure, and ultimately resulted in obesity and metabolic and endocrine disorders (Zhan et al. 2013). Moreover, POMC neurons have been reported to regulate glucose homeostasis via glucose sensing properties (Parton et al. 2007). Therefore, increased POMC-expressing neurons after VSG could contribute to the improved glucose profile induced by HFD. In support of this notion, a recent study showed that the specific role of the alpha MSH receptor, MC4R, in cholinergic preganglionic neurons of the parasympathetic and the sympathetic system after Roux-en-Y gastric bypass (RYGB) in an animal model of diet-induced obesity mice. Similar with our findings, in these mice, the RYGB induced body weight loss was mainly due to an increase in energy expenditure. The mice also had improved insulin sensitivity mainly in the liver, but not skeletal muscle or adipose tissue. However, most of these effects were absent in MC4R knockout mice, suggesting that functional MC4 receptor signaling is required for the full effects of this bariatric surgery on energy expenditure, body weight, and glucose metabolism in mice (Zechner et al. 2013). While the current study cannot rule out the possible involvement of other hypothalamic neuron 
populations in the observed VSG phenotype, the beneficial effects of improved POMC neuron number and function to metabolism is well documented (Schwartz et al. 2000, Ruud et al. 2017). These findings pose a novel mechanism of VSG action via modulation of arcuate neuron populations, and future studies should investigate the potential role of other areas of the hypothalamus involved in energy balance including: the preoptic area, ventromedial nucleus (VMN), dorsomedial nucleus (DMN), and paraventricular nucleus (PVN) (Krashes et al. 2016, Pozo \& Claret 2018).

Our current study has found that there is a negative relationship between dopaminergic and POMC neurons in the hypothalamus. Interestingly, a previous study shows that arcuate dopaminergic neurons inhibit POMCexpressing neurons through synaptic mechanisms, and the gut peptide ghrelin induces excitatory effects of arcuate dopaminergic neurons directly (Zhang \& van den Pol 2016). Notably, reduction in circulating ghrelin levels is one of unique outcomes of VSG (Fig. 3E), which removes the gastric epithelium, the primary source of ghrelin (Chambers et al. 2013, Meek et al. 2016). Thus, it is possible that the reduced ghrelin levels by VSG may be the causative factor of the decreased dopaminergic neurons and the increased POMCexpressing neurons in hypothalamus. In addition, recent findings also revealed that long-term high-fat diet could induce hypothalamic cell inflammation via endoplasmic reticulum (ER) stress, and inflammatory signal transduction, leading to activation of apoptotic signaling pathways and neuron death (De Souza et al. 2005, Milanski et al. 2012, Zhang et al. 2008, Moraes et al. 2009). Interestingly, hypothalamic neuron loss, including POMC-expressing neurons, induced by HFD can be protected by voluntary exercise training partially via an apoptosis-suppressing effect (Laing et al. 2016). Thus, it is tempting to investigate the effects of VSG on hypothalamic inflammation in the future.

Overall, the present study demonstrates the effects of VSG on liver metabolic function independent of energy intake, possibly via hypothalamic neuron-mediated pathways including decreasing dopaminergic neurons and promoting POMC-expressing neurons in the arcuate nucleus of the hypothalamus in HFD-induced obese mice. Although the cellular and molecular mechanisms behind this phenomenon need to be explored further, our findings showed that VSG has a beneficial role in improving metabolic function, and this improvement might be, at least in part, due to altered hypothalamic neuron populations.

(C) 2019 Society for Endocrinology Published by Bioscientifica Ltd. Printed in Great Britain
Supplementary data

This is linked to the online version of the paper at https://doi.org/10.1530/ JOE-18-0658.

\section{Declaration of interest}

The authors declare that there is no conflict of interest that could be perceived as prejudicing the impartiality of the research reported.

\section{Funding}

This work was supported by start-up funds from East Carolina University to $\mathrm{H}$ Huang.

\section{Author contribution statement}

P L, Z R, B L, W B, T L performed all the experiments; P L, Z R, H H analyzed data; $Y Y$ helped to maintain the experimental mice; A P helped POMC, NPY and TH neurons counting; P L, Z Z and $\mathrm{H} \mathrm{H}$ designed the experiments; P L and $\mathrm{H} \mathrm{H}$ wrote the manuscript. All the coauthors reviewed and approved submission of the manuscript.

\section{Acknowledgments}

The authors thank Dr Jingjing Niu at Duke University for VSG training and technical support; Dr Qiang Wu (Department of Biostatistics) at East Carolina University for statistical analysis consulting; Dr Joseph Houmard (Department of Kinesiology) and Dr Walter J Pories (Department of Surgery) at East Carolina University for helpful discussion.

\section{References}

Ballsmider LA, Vaughn AC, David M, Hajnal A, Di Lorenzo PM \& Czaja K 2015 Sleeve gastrectomy and Roux-en-Y gastric bypass alter the gutbrain communication. Neural Plasticity 2015 601985. (https://doi. org/10.1155/2015/601985)

Berthoud HR 2008a Vagal and hormonal gut-brain communication: from satiation to satisfaction. Neurogastroenterology and Motility 20 64-72. (https://doi.org/10.1111/j.1365-2982.2008.01104.x)

Berthoud HR $2008 b$ The vagus nerve, food intake and obesity. Regulatory Peptides 149 15-25. (https://doi.org/10.1016/j.regpep.2007.08.024)

Chambers AP, Kirchner H, Wilson-Perez HE, Willency JA, Hale JE, Gaylinn BD, Thorner MO, Pfluger PT, Gutierrez JA, Tschöp MH, et al. 2013 The effects of vertical sleeve gastrectomy in rodents are ghrelin independent. Gastroenterology 144 50.e5-52.e5. (https://doi. org/10.1053/j.gastro.2012.09.009)

Cummings BP, Bettaieb A, Graham JL, Stanhope KL, Kowala M, Haj FG, Chouinard ML \& Havel PJ 2012 Vertical sleeve gastrectomy improves glucose and lipid metabolism and delays diabetes onset in UCDT2DM rats. Endocrinology 153 3620-3632. (https://doi.org/10.1210/ en.2012-1131)

Dadson P, Landini L, Helmiö M, Hannukainen JC, Immonen H, Honka MJ, Bucci M, Savisto N, Soinio M, Salminen P, et al. 2016 Effect of bariatric surgery on adipose tissue glucose metabolism in different depots in patients with or without type 2 diabetes. Diabetes Care 39 292-299. (https://doi.org/10.2337/dc15-1447)

De Silva A \& Bloom SR 2012 Gut hormones and appetite control: a focus on PYY and GLP-1 as therapeutic targets in obesity. Gut and Liver 6 10-20. (https://doi.org/10.5009/gnl.2012.6.1.10) 
De Souza CT, Araujo EP, Bordin S, Ashimine R, Zollner RL, Boschero AC, Saad MJ \& Velloso LA 2005 Consumption of a fat-rich diet activates a proinflammatory response and induces insulin resistance in the hypothalamus. Endocrinology 146 4192-4199. (https://doi org/10.1210/en.2004-1520)

Denis RGP, Joly-Amado A, Webber E, Langlet F, Schaeffer M, Padilla SL, Cansell C, Dehouck B, Castel J, Delbès AS, et al. 2015 Palatability can drive feeding independent of AgRP neurons. Cell Metabolism 22 646-657. (https://doi.org/10.1016/j.cmet.2015.07.011)

Dietrich MO \& Horvath TL 2013 Hypothalamic control of energy balance: insights into the role of synaptic plasticity. Trends in Neurosciences 36 65-73. (https://doi.org/10.1016/j.tins.2012.12.005)

Do K, Laing BT, Landry T, Bunner W, Mersaud N, Matsubara T, Li P, Yuan Y, Lu Q \& Huang H 2018 The effects of exercise on hypothalamic neurodegeneration of Alzheimer's disease mouse model. PLoS ONE 13 e0190205. (https://doi.org/10.1371/journal. pone.0190205)

Douros JD, Lewis AG, Smith EP, Niu J, Capozzi M, Wittmann A, Campbell J, Tong J, Wagner C, Mahbod P, et al. 2018 Enhanced glucose control following vertical sleeve gastrectomy does not require a $\beta$-cell glucagon-like peptide 1 receptor. Diabetes 67 1504-1511. (https://doi.org/10.2337/db18-0081)

Friedman JE, Dohm GL, Leggett-Frazier N, Elto CW, Tapscott EB, Pories WP \& Caro JF 1992 Restoration of insulin responsiveness in skeletal muscle of morbidly obese patients after weight loss. Effect on muscle glucose transport and glucose transporter GLUT4. Journal of Clinical Investigation 89 701-705. (https://doi.org/10.1172/JCI115638)

Ge X, Yang H, Bednarek MA, Tilleman HG, Chen P, Chen M, Lichtman JS, Wang Y, Dalmas O, Yin Y, et al. 2018 LEAP2 is an endogenous antagonist of ghrelin receptor. Cell Metabolism 27 461.e6-469.e6. (https://doi.org/10.1016/j.cmet.2017.10.016)

Henry B, Yoav A, Eugene B, Michael DJ, Walter P, Kyle F \& Karen S 2004 Bariatric surgery: a systematic review and meta-analysis. JAMA 292 1724-1737. (https://doi.org/10.1001/jama.292.14.1724)

Holman GD \& Cushman SW 1994 Subcellular localization and trafficking of the GLUT4 glucose transporter isoform in insulin-responsive cells. BioEssays 16 753-759. (https://doi.org/10.1002/bies.950161010)

Huang H, Kong D, Byun KH, Ye C, Koda S, Lee DH, Oh BC, Lee SW, Lee B, Zabolotny JM, et al. 2012 Rho-kinase regulates energy balance by targeting hypothalamic leptin receptor signaling. Nature Neuroscience 15 1391-1398. (https://doi.org/10.1038/nn.3207)

Huang H, Lee SH, Ye C, Lima IS, Oh BC, Lowell BB, Zabolotny JM \& Kim YB 2013 ROCK1 in AgRP neurons regulates energy expenditure and locomotor activity in male mice. Endocrinology 154 3660-3670. (https://doi.org/10.1210/en.2013-1343)

Kashyap SR, Bhatt DL, Wolski K, Watanabe RM, Abdul-Ghani M, Abood B, Pothier CE, Brethauer S, Nissen S, Gupta M, et al. 2013 Metabolic effects of bariatric surgery in patients with moderate obesity and type 2 diabetes: analysis of a randomized control trial comparing surgery with intensive medical treatment. Diabetes Care $\mathbf{3 6}$ 2175-2182. (https://doi.org/10.2337/dc12-1596)

Iggo A 1957 Gastric mucosal chemoreceptors with vagal afferent fibres in the cat. Quarterly Journal of Experimental Physiology and Cognate Medical Sciences 42 398-409. (https://doi.org/10.1113/expphysiol.1957. sp001284)

Kershaw EE \& Flier JS 2004 Adipose tissue as an endocrine organ. Journal of Clinical Endocrinology and Metabolism 89 2548-2556. (https://doi. org/10.1210/jc.2004-0395)

Kiefer FW 2017 The significance of beige and brown fat in humans. Endocrine Connections 6 R70-R79. (https://doi.org/10.1530/EC-170037)

Kopelman PG 2000 Obesity as a medical problem. Nature 404 635-643. (https://doi.org/10.1038/35007508)

Krashes MJ, Lowell BB \& Garfield AS 2016 Melanocortin-4 receptorregulated energy homeostasis. Nature Neuroscience 19 206-219. (https://doi.org/10.1038/nn.4202)
Laing BT, Do K, Matsubara T, Wert DW, Avery MJ, Langdon EM, Zheng D \& Huang H 2016 Voluntary exercise improves hypothalamic and metabolic function in obese mice. Journal of Endocrinology 229 109-122. (https://doi.org/10.1530/JOE-15-0510)

Luquet S, Perez FA, Hnasko TS \& Palmiter RD 2005 NPY/AgRP neurons are essential for feeding in adult mice but can be ablated in neonates. Science 310 683-685. (https://doi.org/10.1126/science.1115524)

Meek CL, Lewis HB, Reimann F, Gribble FM \& Park AJ 2016 The effect of bariatric surgery on gastrointestinal and pancreatic peptide hormones. Peptides 77 28-37. (https://doi. org/10.1016/j.peptides.2015.08.013)

Milanski M, Arruda AP, Coope A, Ignacio-Souza LM, Nunez CE, Roman EA, Romanatto T, Pascoal LB, Caricilli AM, Torsoni MA, et al. 2012 Inhibition of hypothalamic inflammation reverses diet-induced insulin resistance in the liver. Diabetes 61 1455-1462. (https://doi. org/10.2337/db11-0390)

Moraes JC, Coope A, Morari J, Cintra DE, Roman EA, Pauli JR, Romanatto T, Carvalheira JB, Oliveira AL, Saad MJ, et al. 2009 Highfat diet induces apoptosis of hypothalamic neurons. PLOS ONE 4 e5045. (https://doi.org/10.1371/journal.pone.0005045)

Murphy KG \& Bloom SR 2006 Gut hormones and the regulation of energy homeostasis. Nature 444 854-859. (https://doi.org/10.1038/ nature05484)

Nadkarni P, Chepurny OG \& Holz GG 2014 Regulation of glucose homeostasis by GLP-1. Progress in Molecular Biology and Translational Science 121 23-65. (https://doi.org/10.1016/B978-0-12-8001011.00002-8)

Parton LE, Ye CP, Coppari R, Enriori PJ, Choi B, Zhang CY, Xu C, Vianna CR, Balthasar N, Lee CE, et al. 2007 Glucose sensing by POMC neurons regulates glucose homeostasis and is impaired in obesity. Nature 449 228-232. (https://doi.org/10.1038/nature06098)

Peterli R, Wölnerhanssen B, Peters T, Devaux N, Kern B, ChristoffelCourtin C, Drewe J, von Flüe M \& Beglinger C 2009 Improvement in glucose metabolism after bariatric surgery: comparison of laparoscopic Roux-en-Y gastric bypass and laparoscopic sleeve gastrectomy: a prospective randomized trial. Annals of Surgery $\mathbf{2 5 0}$ 234-241. (https://doi.org/10.1097/SLA.0b013e3181ae32e3)

Petersen MC, Vatner DF \& Shulman GI 2017 Regulation of hepatic glucose metabolism in health and disease. Nature Reviews Endocrinology 13 572-587. (https://doi.org/10.1038/nrendo.2017.80)

Pozo M \& Claret M 2018 Hypothalamic control of systemic glucose homeostasis: the pancreas connection. Trends in Endocrinology and Metabolism 29 581-594. (https://doi.org/10.1016/j.tem.2018.05.001)

Qian S, Chen H, Weingarth D, Trumbauer ME, Novi DE, Guan X, Yu H, Shen Z, Feng Y, Frazier E, et al. 2002 Neither agouti-related protein nor neuropeptide $\mathrm{Y}$ is critically required for the regulation of energy homeostasis in mice. Molecular and Cellular Biology 22 5027-5035. (https://doi.org/10.1128/MCB.22.14.5027-5035.2002)

Rizzello M, Abbatini F, Casella G, Alessandri G, Fantini A, Leonetti F \& Basso N 2010 Early postoperative insulin-resistance changes after sleeve gastrectomy. Obesity Surgery 20 50-55. (https://doi.org/10.1007/ s11695-009-0017-2)

Ruud J, Steculorum SM \& Brüning JC 2017 Neuronal control of peripheral insulin sensitivity and glucose metabolism. Nature Communications $\mathbf{8}$ 15259. (https://doi.org/10.1038/ncomms15259)

Schauer PR, Bhatt DL, Kirwan JP, Wolski K, Brethauer SA, Navaneethan SD, Aminian A, Pothier CE, Kim ES, Nissen SE, et al. 2014 Bariatric surgery versus intensive medical therapy for diabetes - 3-year outcomes. New England Journal of Medicine 370 2002-2013. (https://doi.org/10.1056/NEJMoa1401329)

Schwartz MW, Woods SC, Porte D Jr, Seeley RJ \& Baskin DG 2000 Central nervous system control of food intake. Nature $\mathbf{4 0 4} 661-671$. (https:// doi.org/10.1038/35007534)

Sharma AM 2003 Obesity and cardiovascular risk. Growth Hormone and IGF Research 13 (Supplement A) S10-S17. (https://doi.org/10.1016/ S1096-6374(03)00047-9) 
Uyama N, Geerts A \& Reynaert H 2004 Neural connections between the hypothalamus and the liver. Anatomical Record: Part A, Discoveries in Molecular, Cellular and Evolutionary Biology 280 808-820. (https://doi. org/10.1002/ar.a.20086)

Víctor V, Helena A, Albert L, Maria TS, Juan AB, José MF, Joaquín R, Roser F, Roberto C, Eva P, et al. 2012 Surgically induced weight loss by gastric bypass improves non-alcoholic fatty liver disease in morbid obese patients. World Journal of Hepatology 27 382-388. (https://doi. org/10.4254/wjh.v4.i12.382)

Vidal J, Ibarzabal A, Romero F, Delgado S, Momblán D, Flores L \& Lacy A 2008 Type 2 diabetes mellitus and the metabolic syndrome following sleeve gastrectomy in severely obese subjects. Obesity Surgery 18 1077-1082. (https://doi.org/10.1007/s11695-008-9547-2)

Wu J, Bostrom P, Sparks LM, Ye L, Choi JH, Giang AH, Khandekar M, Virtanen KA, Nuutila P, Schaart G, et al. 2012 Beige adipocytes are a distinct type of thermogenic fat cell in mouse and human. Cell $\mathbf{1 5 0}$ 366-376. (https://doi.org/10.1016/j.cell.2012.05.016)
Zechner JF, Mirshahi UL, Satapati S, Berglund ED, Rossi J, Scott MM, Still CD, Gerhard GS, Burgess SC, Mirshahi T, et al. 2013 Weightindependent effects of Roux-en-Y gastric bypass on glucose homeostasis via melanocortin-4 receptors in mice and humans. Gastroenterology 144 580.e7-590.e7. (https://doi.org/10.1053/j.gastro.2012.11.022)

Zhan C, Zhou J, Feng Q, Zhang JE, Lin S, Bao J, Wu P \& Luo M 2013 Acute and long-term suppression of feeding behavior by POMC neurons in the brainstem and hypothalamus, respectively. Journal of Neuroscience 33 3624-3632. (https://doi.org/10.1523/ JNEUROSCI.2742-12.2013)

Zhang X \& van den Pol AN 2016 Hypothalamic arcuate nucleus tyrosine hydroxylase neurons play orexigenic role in energy homeostasis. Nature Neuroscience 19 1341-1347. (https://doi.org/10.1038/nn.4372)

Zhang X, Zhang G, Zhang H, Karin M, Bai H \& Cai D 2008 Hypothalamic IKKbeta/NF-kappaB and ER stress link overnutrition to energy imbalance and obesity. Cell 135 61-73. (https://doi.org/10.1016/j. cell.2008.07.043)

Received in final form 26 February 2019

Accepted 14 March 2019

Accepted Preprint published online 14 March 2019 (c) 2019 Society for Endocrinology Published by Bioscientifica Ltd.
Printed in Great Britain 